\title{
Impact of Inter-hospital Transfer on the Outcomes of Primary Percutaneous Coronary Intervention
}

\author{
Pedro Beraldo de Andrade', Marden André Tebet ${ }^{2}$, Ederlon Ferreira Nogueira ${ }^{3}$, Fábio Salerno Rinaldi ${ }^{4}$, \\ Vinícius Cardozo Esteves ${ }^{5}$, Mônica Vieira Athanazio de Andrade ${ }^{6}$, Robson Alves Barbosa ${ }^{7}$, \\ André Labrunie ${ }^{8}$, Luiz Alberto Mattos ${ }^{9}$
}

\begin{abstract}
Background: Delays resulting from the transfer to perform primary percutaneous coronary intervention $(\mathrm{PCl})$ have a negative impact on the benefits of the procedure. Methods: Prospective registry aimed at comparing the results of primary $\mathrm{PCl}$ in patients with ST-segment elevation myocardial infarction (STEMI) admitted or transferred to an interventional cath lab equipped hospital. Results: Between February 2009 and December 2011, 319 patients were included in the study with mean age of $59.8 \pm 12$ years, $28.5 \%$ were female and $22.3 \%$ were diabetics. Patients transferred for primary $\mathrm{PCl}$ $(\mathrm{n}=201)$ had longer door-to-balloon time $(86.4 \pm 26.6 \mathrm{~min}$ vs $69 \pm 22.6 \mathrm{~min} ; \mathrm{P}<0.0001)$, a non-significant decrease in ST-segment elevation resolution $(83.5 \%$ vs $90.4 \% ; \mathrm{P}=0.18)$, final TIMI 3 flow $(90.1 \%$ vs $94.1 \%$; $\mathrm{P}=0.30)$, myocardial blush grade $3(74.3 \%$ vs $78.8 \% ; P=0.22)$ and angiographic success $(90.1 \%$ vs $94.1 \% ; \mathrm{P}=0.30)$, and a non-significant increase in major bleeding ( $2 \%$ vs $0.9 \% ; P=0.20)$ and hospital mortality $(6.5 \%$ vs $4 \%$; $P=0.29)$. Conclusions: The referral of patients with STEMI directly to an interventional cath lab equiped hospital is associated with shorter door-toballoon time and non-significant improvement of reperfusion markers and mortality.
\end{abstract}

DESCRIPTORS: Myocardial infarction. Angioplasty. Patient transfer. Reperfusion. Mortality.

\section{RESUMO}

Impacto da Transferência Inter-hospitalar
nos Resultados da Intervenção Coronária
Percutânea Primária

Introdução: Atrasos decorrentes da transferência para realização de intervenção coronária percutânea (ICP) primária impactam negativamente os benefícios do procedimento. Métodos: Registro prospectivo objetivando comparar os resultados da ICP primária entre pacientes com infarto agudo do miocárdio com supradesnivelamento do segmento ST (IAMCSST) admitidos ou transferidos para hospital equipado com laboratório de intervenção. Resultados: Entre fevereiro de 2009 e dezembro de 2011, foram incluídos 319 pacientes, com média de idade de $59,8 \pm 12$ anos, $28,5 \%$ do sexo feminino e $22,3 \%$ diabéticos. Pacientes transferidos para realização de ICP primária $(n=201)$ apresentaram tempo porta-balão mais longo $(86,4 \pm 26,6 \mathrm{~min}$ vs. $69 \pm 22,6$ min; $P<0,0001)$, diminuição não significativa da resolução do supradesnivelamento do segmento ST $(83,5 \%$ vs. $90,4 \%$; $\mathrm{P}=0,18)$, do fluxo final TIMI $3(90,1 \%$ vs. $94,1 \%$; $\mathrm{P}=0,30)$, do blush miocárdico grau $3(74,3 \%$ vs. $78,8 \% ; \mathrm{P}=0,22)$ e do sucesso angiográfico $(90,1 \%$ vs. $94,1 \%$; $P=0,30)$, e incremento não significativa de sangramento grave ( $2 \%$ vs. $0,9 \%$; $\mathrm{P}=0,20)$ e mortalidade hospitalar $(6,5 \%$ vs. $4 \% ; \mathrm{P}=0,29)$. Conclusões: $O$ encaminhamento do paciente com IAMCSST diretamente a hospital com laboratório de intervenção associa-se a menor tempo portabalão e melhora não significativa dos marcadores de reperfusão e da mortalidade.

DESCRITORES: Infarto do miocárdio. Angioplastia. Transferência de pacientes. Reperfusão. Mortalidade.

\footnotetext{
${ }^{1}$ Doctoral Student. Interventionist Cardiologist Physician at Santa Casa de Marília. Marília, SP, Brazil.

2 Interventionist Cardiologist Physician at Santa Casa de Marília. Marília, SP, Brazil.

3 Interventionist Cardiologist Physician at Hospital do Coração de Londrina. Londrina, PR, Brazil.

4 Interventionist Cardiologist Physician at Santa Casa de Marília. Marília, SP, Brazil.

${ }^{5}$ Interventionist Cardiologist Physician at Hospital e Maternidade Brasil

- Rede D’Or. Santo André, SP, Brazil.

${ }^{6}$ Specialist in Cardiovascular Nursing Cardiology Nurse at Santa Casa de Marília. Marília, SP, Brazil.
}

\footnotetext{
7 Specialist nurse in Cardiovascular nursing at Santa Casa de Marília. Marília, SP, Brazil.

${ }^{8}$ Specialist in Cardiovascular Nursing Nurse at Hospital do Coração de Londrina. Londrina, PR, Brazil.

${ }_{9}^{9}$ Doctor. Interventionist Cardiologist Physician at Instituto Dante Pazzanese de Cardiologia. São Paulo, SP, Brazil.
}

Correspondence to: Pedro Beraldo de Andrade. Avenida Vicente Ferreira, 828 - Marília, SP, Brazil - CEP 17515-900

E-mail: pedroberaldo@gmail.com

Received on: 9/24/2012 • Accepted on: 11/19/2012 
$\mathbf{P}$ rimary percutaneous coronary intervention $(\mathrm{PCl})$ is the preferred reperfusion strategy for acute myocardial infarction with ST segment elevation myocardial infarction (STEMI), provided that it is performed within the first 90 minutes after the diagnosis by experienced staff at a high-volume center. ${ }^{1}$ Until 2006, statistics from the United States showed that approximately 25\% of hospitals had no access to primary $\mathrm{PCl}$ and that only $10 \%$ of patients were treated within the optimal time range suggested by the guidelines. ${ }^{2}$ Updated data have reported an improved mean door-to-balloon time of 64.5 minutes, increasing to 121 minutes in transferred patients. ${ }^{3}$ In Brazil, preliminary results from the Clinical Practice Registry for Acute Coronary Syndrome (ACCEPT), which represents 47 national referral institutions, have observed a mean 125-minute delay between the diagnosis and the completion of the procedure; only $36 \%$ of cases were effectively treated in less than 90 minutes. $^{4}$

Strategies aimed at reducing the delay when performing primary $\mathrm{PCl}$ are a topic of current and increasing interest. A meta-regression analysis of 5,741 patients in 11 randomized trials demonstrated the superiority of transferring patients to undergo primary $\mathrm{PCI}$ compared with performing local fibrinolysis in reducing mortality, recurrent myocardial infarction (MI) and stroke. ${ }^{5}$ However, these findings are applicable to the patients included in these studies, which were characterized by reduced door-to-balloon times, and thus not applicable to the real world, in which delays arising from patient transfers are commonly observed. In this scenario, the benefits determined by mechanical reperfusion can be attenuated or lost completely.

This study aimed to evaluate the impact of interhospital transfer on the efficacy and safety outcomes in patients with STEMI undergoing primary $\mathrm{PCl}$ in the city of Marília, SP, Brazil, which offers an integrated and efficient care system for cardiovascular emergencies.

\section{METHODS}

The present study analyzed a prospective registry of consecutive patients diagnosed with STEMI who underwent primary $\mathrm{PCl}$ (within 12 hours of evolution) in Marília, SP, Brazil. With an estimated population of 226,000 inhabitants (based on the most recent census of the Brazilian Institute of Geography and Statistics [Instituto Brasileiro de Geografia e Estatística - IBGE]), the city has 12 basic health units (BHU) and two emergency hospitals $(\mathrm{EH})$ that belong to the Brazilian Unified Health System (Sistema Único de Saúde - SUS) network. Two tertiary hospitals, one of which is equipped with an interventional cardiology lab that operates 24 hours a day, seven days a week, with an annual volume of over 500 annual $\mathrm{PCl}$ procedures, constituted the reference point for treating cardiovascular emergencies. Transportation between the basic units and the tertiary hospitals, as well as inter-hospital transportation (distance of approximately $2 \mathrm{~km}$ ), are performed by the Emergency Mobile Care Service (Serviço de Atendimento Móvel de Urgência - SAMU). Patients with a pre-hospital diagnosis of STEMI are taken directly to the interventional laboratory, after telephone contact with the staff in charge, thus preventing delays arising from the necessity to go through the emergency department.

Patients who were transferred for primary percutaneous coronary intervention were compared to those who were admitted directly to a hospital capable of performing the procedure. The evaluated efficacy outcomes included the angiographic success rate, restoration of epicardial Thrombolysis in Myocardial Infarction (TIMI) 3 flow, myocardial blush grade 3, resolution of ST-segment elevation $>50 \%$, and in-hospital mortality. The safety outcome consisted of severe bleeding. In accordance with the classification of the Bleeding Academic Research Consortium, ${ }^{6}$ severe bleeding was defined according to the following categories: type 3 ([3a] bleeding with a decrease in haemoglobin $\geq 3$ and $<5 \mathrm{~g} / \mathrm{dL}$ or a transfusion of packed red blood cells; [3b] bleeding with a decrease in haemoglobin $\geq 5$ g/ $\mathrm{dL}$, cardiac tamponade, bleeding requiring surgical intervention, or bleeding requiring intravenous vasoactive drugs; [3c] intracranial haemorrhage, as confirmed by autopsy or subcategories, imaging examinations or lumbar puncture, or intraocular bleeding with vision impairment); or type 5 ([5a] probable fatal bleeding, [5b] definite fatal bleeding). Transportation time was defined as the interval between the electrocardiogram (EKG) diagnosis and the patient's arrival at the interventional laboratory. Symptom-to-balloon time was defined as the interval between symptom onset and the crossing of the lesion with pre-dilatation balloon, manual aspiration catheter, or stent. Door-to-balloon time was defined as the interval between the EKG diagnosis and crossing the lesion with pre-dilatation balloon, manual aspiration catheter, or stent.

The statistical analysis was performed with SPSS software, release 12.0 (SPSS Inc. - Chicago, USA). Categorical variables were expressed as absolute numbers and their percentages and were compared with the chi-squared test or Fisher's exact test. Continuous variables were expressed as means and standard deviations and were compared using Student's $t$-test. Statistically significant results were determined with a P-value $<0.05$.

\section{RESULTS}

Between February 2009 and December 2011, 319 patients who were diagnosed with STEMI and underwent primary $\mathrm{PCl}$ were included in the study, 118 of whom were directly admitted to a tertiary hospital equipped with an interventional cardiology laboratory; 201 patients were initially treated at tertiary hospitals lacking these facilities, and were later transferred to another hospital to undergo the procedure. 
The clinical and demographic characteristics of the sample are shown in Table 1 . The subjects' mean age was $59.8 \pm 12$ years; $71.5 \%$ were males, and $22.3 \%$ had diabetes mellitus. The characteristics of the procedures were similar between groups, except for higher transportation time $(52.5 \pm 23.4$ minutes vs. $14.1 \pm$ 11.4 minutes; $\mathrm{P}<0.0001)$, longer symptom-to-balloon time $(5 \pm 2.2$ hours vs. $3.3 \pm 2.2$ hours; $\mathrm{P}<0.0001)$, and higher door-to-balloon time $(86.4 \pm 26.6$ minutes vs. $69 \pm 22.6$ minutes; $P<0.0001)$ in the transferred patients (Table 2).

The predominant arterial access route was the transradial approach $(96.6 \%)$, whereas the femoral approach was used in nine cases $(2.8 \%)$, and the ulnar approach in two cases $(0.6 \%)$. The failure rate of the transradial approach was $0.97 \%$ (three cases), due to chronic occlusion of the innominate artery, severe tortuosity of the radial artery, and lack of support for the $\mathrm{PCl}$ performance. In $99 \%$ of the procedures, $6 \mathrm{~F}$ introducers were used; stents were implanted in $95.9 \%$ of cases.

The patients who were transferred for primary $\mathrm{PCl}$ had lower rates of resolution of ST-segment elevation, final TIMI 3 flow, myocardial blush grade 3, and angiographic success, with a non-significant increase of severe bleeding and in-hospital mortality (Table 3).

The main determinants of inter-hospital transfer delay include the delays related to patient referral (e.g., authorization by the Hospital Bed Regulatory System and SAMU availability) in 190 cases (94.5\%), factors related to the intervention center (e.g., availability of a multidisciplinary team and simultaneous use of the unit for another procedure) in nine cases $(4.5 \%)$, and delays in inter-hospital transportation in two cases (1\%) (Figure 1).

\section{DISCUSSION}

The study results demonstrate that the organization and use of an integrated care system for patients with STEMI, even among those patients transferred for primary percutaneous coronary intervention, achieve a door-to-balloon time within the range recommended by the guidelines. However, the present findings should be interpreted with caution. The choice of strategy for inter-hospital transfers necessarily promotes an increase in transportation time, symptom-to-balloon time, and door-to-balloon time, to the detriment of local fibrinolysis. ${ }^{7}$ In Marília, the inter-hospital distance is only 2 $\mathrm{km}$, and the city does not have the difficulties that are inherent to the urban traffic of metropolitan regions. In addition, although not statistically significant, the transferred patients had lower resolution rates of S-T segment elevation, final TIMI 3 flow, myocardial blush grade 3 , and angiographic success, with increased rates of severe bleeding and in-hospital mortality.

In fact, data from the National Registry of Myocardial Infarction (NRMI) show that the benefit of transfers for primary $\mathrm{PCl}$ compared to fibrinolysis is time-dependent. Mortality rates alone, mortality/reinfarction rates, and mortality/reinfarction/stroke rates are lower and more favourable compared to primary $\mathrm{PCl}$ when the delay to the start of treatment is less than 60 minutes or $60-90$ minutes; the benefit becomes questionable when this time exceeds 90 minutes and is absent after 120 minutes. $^{8}$ Thus, it becomes imperative to develop strategies that facilitate access to primary $\mathrm{PCl}$ and reduce the doorto-balloon time. The most common attributable causes of delay for inter-hospital transfer are those related to referral (e.g., waiting for transportation; unclear or nondiagnostic EKG), followed by delays in the intervention

Table 1

Basal clinical and demographic characteristics

\begin{tabular}{|c|c|c|c|c|}
\hline Variables & $\begin{array}{l}\text { Overall } \\
n=319\end{array}$ & $\begin{array}{c}\text { Transferred } \\
n=201\end{array}$ & $\begin{array}{l}\text { Not transferred } \\
\qquad n=118\end{array}$ & $\mathbf{P}$ \\
\hline Mean age, years & $59.8 \pm 1.2$ & $58.2 \pm 11.6$ & $62.6 \pm 12.3$ & 0.001 \\
\hline Females, n (\%) & $91(28.5)$ & $61(30.3)$ & $30(25.4)$ & 0.37 \\
\hline Diabetes mellitus, n (\%) & $71(22.3)$ & $36(17.9)$ & $35(29.7)$ & 0.017 \\
\hline Arterial hypertension, $\mathrm{n}(\%)$ & $210(65.8)$ & $130(64.7)$ & $81(68.6)$ & 0.54 \\
\hline Dyslipidemia, n (\%) & $93(29.2)$ & $47(23.4)$ & $46(38.9)$ & 0.004 \\
\hline Current smoking, n (\%) & $147(46.1)$ & $106(52.7)$ & $41(34.7)$ & 0.002 \\
\hline Family history of heart failure, $\mathrm{n}(\%)$ & $49(15.4)$ & $26(12.9)$ & $23(19.5)$ & 0.15 \\
\hline Previous acute myocardial infarction, n (\%) & $19(5.9)$ & $11(5.5)$ & $8(6.8)$ & 0.63 \\
\hline Previous CABG surgery, n (\%) & $6(1.9)$ & $3(1.5)$ & $3(2,5)$ & 0.67 \\
\hline Previous $\mathrm{PCl}, \mathrm{n}(\%)$ & $19(15.4)$ & $8(4)$ & $11(9.3)$ & 0.08 \\
\hline
\end{tabular}

CABG, coronary artery bypass graft; $\mathrm{PCl}$, percutaneous coronary intervention. 
Table 2

Procedural characteristics

\begin{tabular}{|c|c|c|c|c|}
\hline Variables & $\begin{array}{l}\text { Overall } \\
n=319\end{array}$ & $\begin{array}{c}\text { Transferred } \\
n=201\end{array}$ & $\begin{array}{l}\text { Not transferred } \\
\qquad n=118\end{array}$ & $\mathbf{P}$ \\
\hline Call between 7AM and 7PM, n (\%) & $192(60,2)$ & $123(61.2)$ & $68(57.6)$ & 0.56 \\
\hline Call between 7 PM and 7 AM, n (\%) & $127(39.8)$ & $78(38.8)$ & $50(42.4)$ & 0.56 \\
\hline Weekends, n (\%) & $101(31.7)$ & $66(32.8)$ & $35(30)$ & 0.62 \\
\hline Transportation time, minutes & $38.1 \pm 27.1$ & $52.5 \pm 23.4$ & $14.1 \pm 11.4$ & $<0.0001$ \\
\hline Symptom-to-balloon time, hours & $4.3 \pm 2.3$ & $5 \pm 2.2$ & $3.3 \pm 2.2$ & $<0.0001$ \\
\hline Door-to-balloon time, minutes & $79.9 \pm 26.5$ & $86.4 \pm 26.6$ & $69 \pm 22.6$ & $<0.0001$ \\
\hline Single-vessel coronary disease, n (\%) & $158(49.5)$ & $103(51.2)$ & $55(46.6)$ & 0.49 \\
\hline Anterior descending culprit artery, n (\%) & $147(46.1)$ & $98(48.8)$ & $50(42.4)$ & 0.30 \\
\hline Killip III-IV, n (\%) & $32(10.1)$ & $19(9.7)$ & $12(10.7)$ & 0.83 \\
\hline Transradial access, $\mathrm{n}(\%)$ & $308(96.6)$ & $196(97.5)$ & $112(94.9)$ & 0.34 \\
\hline Duration of procedure, minutes & $45.1 \pm 20.5$ & $43.7 \pm 17.9$ & $47.6 \pm 24.2$ & 0.10 \\
\hline Fluoroscopy time, minutes & $11.3 \pm 7.4$ & $10.8 \pm 6.7$ & $11.9 \pm 8.5$ & 0.20 \\
\hline Type $\mathrm{B}_{2} / \mathrm{C}$ lesion, n (\%) & $290(90.9)$ & $183(91)$ & $107(90.7)$ & $>0.99$ \\
\hline Aspiration catheter, n (\%) & $174(54.5)$ & $108(53.7)$ & $66(55,9)$ & 0.73 \\
\hline IIb/IIla glycoprotein inhibitor, n (\%) & $230(72.1)$ & $143(71.1)$ & $87(73.7)$ & 0.70 \\
\hline 0-1 pre TIMI flow, n (\%) & $273(85.6)$ & $174(86.6)$ & $99(83.8)$ & 0.51 \\
\hline Pre-dilation, n (\%) & $179(56.1)$ & $118(58.7)$ & $61(51.7)$ & 0.24 \\
\hline Stent implantation, n (\%) & $306(95.9)$ & $195(97)$ & $111(94.1)$ & 0.24 \\
\hline Intra-aortic balloon, n (\%) & $5(1.6)$ & $1(0.5)$ & $4(3.4)$ & 0.064 \\
\hline
\end{tabular}

Table 3

Efficacy and safety outcomes

\begin{tabular}{|c|c|c|c|c|}
\hline Variables & $\begin{array}{l}\text { Overall } \\
n=319\end{array}$ & $\begin{array}{c}\text { Transferred } \\
\mathbf{n}=\mathbf{2 0 1}\end{array}$ & $\begin{array}{l}\text { Not transferred } \\
\quad n=118\end{array}$ & $\mathbf{P}$ \\
\hline $\begin{array}{l}\text { Resolution of ST-segment elevation } \\
>50 \%, \mathrm{n}(\%)\end{array}$ & $207(86.6)$ & $121(83.5)$ & $106(90.4)$ & 0.18 \\
\hline Final TIMI 3 flow, n (\%) & $292(91.5)$ & $181(90.1)$ & $111(94.1)$ & 0.30 \\
\hline Myocardial blush grade 3, n (\%) & $232(74.8)$ & $149(74.3)$ & $93(78.8)$ & 0.22 \\
\hline Angiographic success, n (\%) & $292(91.5)$ & $181(90.1)$ & $111(94.1)$ & 0.30 \\
\hline Severe bleeding, n (\%) & $6(1.9)$ & $4(2)$ & $2(0.9)$ & 0.20 \\
\hline In-hospital mortality, n (\%) & $18(5.6)$ & $13(6.5)$ & $5(4)$ & 0.29 \\
\hline
\end{tabular}

center (e.g., staff availability and procedure complexity) and the transportation of patients (e.g., distances, weather and geographical features). ${ }^{9}$ In the present study, the major factors were waiting for the transportation and bureaucratic transfer regulations.
The direct transportation of patients with a prehospital diagnosis of STEMI to the interventional cardiology lab, preceded by contact and team awareness, is a simple measure that is capable of increasing by three-fold the proportion of patients treated within 


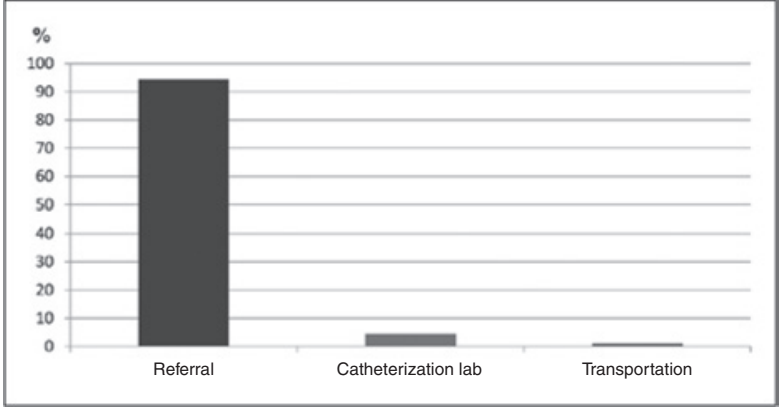

Figure 1 - Determinant factors of inter-hospital transfer delays.

the recommended therapeutic window, which results in higher rates of final TIMI 3 flow; this outcome, in turn, is an important predictor of long-term survival. ${ }^{10}$ Moreover, the use and activation of emergency medical services, consisting of professionals trained in the interpretation of 12-lead EKG and the possibility of transmitting the electrocardiographic tracing elsewhere (telemetry), culminating with direct patient transportation to the interventional laboratory, have been shown to significantly reduce reperfusion times and mortality rates at six months for these patients. ${ }^{11,12}$

The role of the pharmaco-invasive strategy in this context is still debatable. Although the immediate performance of $\mathrm{PCl}$ after fibrinolysis as a facilitating tool has promoted increased mortality when compared with primary $\mathrm{PCl}$ alone, ${ }^{13}$ more recent studies have demonstrated favorable outcomes for the routine transfer of patients undergoing fibrinolysis followed by invasive stratification within the first six to 24 hours after lytic administration. ${ }^{14-17}$ Despite the natural interest in establishing a single protocol for the care of patients with STEMI, including a universal and standard reperfusion therapy, the high variability in the results comparing transfer for primary $\mathrm{PCl}$ and fibrinolysis is influenced by the delay to the start of treatment, the patient's risk profile, and the experience of the local staff; the hospital structure predicts the adoption of an individualized analysis and the decision-making process based on these factors.

\section{Study Limitations}

The limitations of this study include the fact that it was observational and nonrandomized, the limited number of patients (which hinders the inference of efficacy and safety outcomes), the inability to determine the actual interval between the patient's admission time and the procedure start time (which is why the door-to-balloon time was chosen), and the absence of clinical information after the hospital discharge, given the high rate of morbidity and cumulative mortality in this clinical setting.

\section{CONCLUSIONS}

In spite of an integrated emergency system, which allows for an inter-hospital transfer time interval $<60$ minutes, referring a patient diagnosed with STEMI directly to a hospital equipped with an interventional laboratory is associated with decreased total ischemia time, reduced door-to-balloon time, improved myocardial reperfusion markers, and a non-significant decrease in hospital mortality.

\section{CONFLICT OF INTEREST}

The authors declare no conflicts of interest.

\section{REFERENCES}

1. Piegas LS, Feitosa G, Mattos LA, Nicolau JC, Rossi Neto JM, Timerman A, et al.; Sociedade Brasileira de Cardiologia. IV diretriz da sociedade brasileira de cardiologia sobre tratamento do infarto agudo do miocárdio com supradesnível do segmento ST. Arq Bras Cardiol. 2009;93(6 Supl 2): e179-e264.

2. Gibson CM, Pride YB, Frederick PD, Pollack CV Jr, Canto JG, Tiefenbrunn AJ, et al. Trends in reperfusion strategies, door-toneedle and door-to-balloon times, and in-hospital mortality among patients with ST-segment elevation myocardial infarction enrolled in the National Registry of Myocardial Infarction from 1990 to 2006. Am Heart J. 2008;156(6):1035-44.

3. Dehmer GJ, Weaver D, Roe MT, Beland SM, Fitzgerald S, Hermann A, et al. A contemporary view of diagnostic cardiac catheterization and percutaneous coronary intervention in the United States: a report from the CathPCI Registry of the National Cardiovascular Data Registry, 2012 through June 2011. J Am Coll Cardiol. 2012;60(20):2017-31.

4. Mattos LA, Santos ES, Reis H, Romano E, Petriz J, Sousa AC, et al. Clinical predictors of major clinical events 30-days after an acute coronary syndrome: insights from Brazilian Cardiovascular Registry ACCEPT [abstract]. J Am Coll Cardiol. 2012;59(13s1):E365-E365

5. De Luca G, Biondi-Zoccai G, Marino P. Transferring patients with ST-segment elevation myocardial infarction for mechanical reperfusion: a meta-regression analysis of randomized trials. Ann Emerg Med. 2008;52(6):665-76.

6. Mehran R, Rao SV, Bhatt DL, Gibson CM, Caixeta A, Eikelboom J, et al. Standardized bleeding definitions for cardiovascular clinical trials: a consensus report from the Bleeding Academic Research Consortium. Circulation. 2011;123(23):2736-47.

7. Manari A, Ortolani P, Guastaroba P, Casella G, Vignali L, Varani $E$, et al. Clinical impact of an inter-hospital transfer strategy in patients with ST-elevation myocardial infarction undergoing primary angioplasty: the Emilia-Romagna ST-segment elevation acute myocardial infarction network. Eur Heart J. 2008;29(15):183442.

8. Pinto DS, Frederick PD, Chakrabarti AK, Kirtane AJ, Ullman E, Dejam A, et al. Benefit of transferring ST-segment-elevation myocardial infarction patients for percutaneous coronary in tervention compared with administration of onsite fibrinolytic declines as delays increase. Circulation. 2011;124(23):2512-21.

9 Miedema MD, Newell MC, Duval S, Garberich RF, Handran CB Larson DM, et al. Causes of delay and associated mortality in patients transferred with ST-segment-elevation myocardial infarction. Circulation. 2011;124(15):1636-44.

10. Dieker HJ, Liem SSB, Aidi HE, van Grunsven P, Aengevaeren WRM, Brouwer MA, et al. Pre-hospital triage for primary angioplasty. JACC Cardiovasc Interv. 2010;3(7):705-11. 
11. Mathews R, Peterson ED, Li S, Roe MT, Glickman SW, Wiviott SD, et al. Use of emergency medical service transport among patients with ST-segment-elevation myocardial infarction: findings from the National Cardiovascular Data Registry Acute Coronary Treatment Intervention Outcomes Network Registry - get with the Guidelines. Circulation. 2011;124(2): 154-63.

12. Le May MR, Wells GA, So DY, Glover CA, Froeschl M, Maloney J, et al. Reduction in mortality as a result of direct transport from the field to a receiving center for primary percutaneous coronary intervention. J Am Coll Cardiol. 2012;60(14):1223-30.

13. Assessment of the Safety and Efficacy of a New Treatment Strategy with Percutaneous Coronary Intervention (ASSENT-4 $\mathrm{PCl})$ Investigators. Primary versus tenecteplase-facilitated percutaneous coronary intervention in patients with ST-segment elevation acute myocardial infarction (ASSENT-4 PCI): randomized trial. Lancet. 2006;367(9510):569-78.

14. Cantor WJ, Fitchett D, Borgundvaag B, Ducas J, Heffernan M, Cohen EA, et al.; TRANSFERAMI Trial Investigators. Routine early angioplasty after fibrinolysis for acute myocardial infarction. N Engl J Med. 2009;360(260):2705-18.

15. Di Mario C, Dudek D, Piscione F, Mielecki W, Savonitto S, Murena $\mathrm{E}$, et al. Immediate angioplasty versus standard therapy with rescue angioplasty after thrombolysis in the Combined Abciximab Reteplase Stent Study in Acute Myocardial Infarction (CARESSinAMI): an open, randomised, multicentre trial. Lancet. 2008;371(9612):559-68.

16. Caluza ACV, Barbosa AH, Gonçalves I, Oliveira CAL, Matos LN, Zeefried C, et al. Rede de infarto com supradesnivelamento de ST: sistematização em 205 casos diminui eventos clínicos na Rede Pública. Arq Bras Cardiol. 2012;99(5):1040-8.

17. Steg PG, James SK, Atar D, Badano LP, Lundqvist CB, Borger MA et al. ESC guidelines for the management of acute myocardial infarction in patients presenting with ST-segment elevation: the task force on the management of ST-segment elevation acute myocardial infarction of the European Society of Cardiology (ESC). Eur Heart J. 2012;33(20):2569-619. 